Красинский Владислав Вячеславович, научный сотрудник НИИ проблем укрепления законности и правопорядка Генпрокуратуры Российской Федерации

Источник публикации: Красинский В.В. Борьба с отмыванием денежных средств в ходе выборов: проблема и возможные пути ее разрешения // Право и политика. 2003. № 6. С. 54-63; www.krasinskiy.ru

\title{
БОРЬБА С ОТМЫВАНИЕМ ДЕНЕЖНЫХ СРЕДСТВ В ХОДЕ ВЫБОРОВ: ПРОБЛЕМА И ВОЗМОЖНЫЕ ПУТИ ЕЕ РАЗРЕШЕНИЯ
}

Неуклонное возрастание стоимости избирательных кампаний, поиск и апробирование новых выборных технологий, острота конкуренции различных политических сил, участвующих в выборах, приводят их к необходимости использования собственных источников финансирования и выработке самостоятельной тактики расходования полученных средств. В этой связи отдельные кандидаты и политические партии добровольно или вынужденно прибегают к помощи преступных групп, подконтрольных им коммерческих структур и отмывают в ходе выборов незаконно полученные денежные средства. Об актуальности данной проблемы свидетельствует и Послание Президента России В.Путина Федеральному Собранию Российской Федерации, в котором отмечается, что «рынок предвыборных технологий в значительной степени является сегодня одним из секторов теневой экономики» ${ }^{1}$.

Следует отметить, что процесс отмывания денежных средств в период выборов носит многофункциональный характер.

Прежде всего, отмывание непосредственно направлено на финансирование расходов, связанных с выборами.

Одновременно, используемый в ходе выборов криминальный капитал обеспечивает политизацию организованной преступности. Это одна из

${ }^{1}$ См.: Российская газета. 2003. 17 мая. 
важнейших функций отмывания денежных средств в ходе выборов, поскольку на базе легализованных денег осуществляется сращивание организованной преступности с органами государственной власти и управления путем коррумпирования должностных лиц, продвижения представителей преступных групп в структуры государственной власти и управления. В последующем, «отмытые» в период выборов деньги инвестируются в различные отрасли экономики, что влечет за собой дальнейшую концентрацию экономической и политической власти в руках криминалитета.

Наконец, наращивание экономической и финансовой мощи организованными преступными группами ведет к подрыву не только экономической сферы, но и основ демократического конституционного строя Российской Федерации.

Все это подтверждает актуальность противодействия отмыванию денежных средств в ходе выборов.

Вместе с тем, анализ литературы показывает, что проблема борьбы с этим явлением является малоизученной и неисследованной в теоретическом плане. Имеющиеся наработки по противодействию отмывания (легализации) денежных средств, как правило, связаны только с финансово-кредитными институтами и экономическими мерами ${ }^{2}$. Особое место занимают труды В.М.Алиева, который изучил понятийнокатегориальный аппарат отмывания незаконных доходов и проанализировал социально-правовые аспекты данной проблематики ${ }^{3}$.

2 См.: Тосунян Г.А., Викулин А.Ю. Противодействие легализации (отмыванию) денежных средств в финансово-кредитной системе. Опыт, проблемы, перспективы. М.: Дело, 2001 г., Ларичев В.A. Правовые меры борьбы с отмыванием незаконных доходов // Законодательство и экономика. 1999. № 11 (189)., Проблемы борьбы с отмыванием денежных средств или иного имущества, приобретенных незаконным путем // Государство и право. 2001. № 2. С. 106-119.

3 См.: Алиев B.M. К вопросу о некоторых понятиях отмывания доходов // Журнал российского права. 1999. № 7-8., Алиев В.M. Легализация доходов, 
Необходимо подчеркнуть, что применительно к избирательному процессу попытки проведения комплексного научного исследования вопросов отмывания денежных средств до настоящего времени не предпринимались. C учетом изложенного, для осуществления эффективного противодействия отмыванию денежных средств в ходе выборов и оптимизации правоприменительной практики в данной сфере требуются четкое определение и выработка единого подхода к понятию отмывания (легализации) денежных средств в ходе выборов.

Здесь необходимо сделать ряд важных оговорок.

Во-первых, процесс отмывания денежных средств происходит постоянно. Во-вторых, в целях настоящей статьи акцент делается не на использовании в ходе выборов денежных средств или имущества финансовопромышленных групп (это стало своеобразной нормой избирательного процесса), а на финансирование выборов представителями организованных преступных групп. В-третьих, представляется необходимым затронуть проблему партийной коррупции как одну из составляющих отмывания денежных средств в ходе выборов ${ }^{4}$.

Процесс отмывания денежных средств в ходе выборов является частным случаем отмывания доходов от преступной деятельности. Поэтому при осуществлении юридической квалификации деяний, подозрительных на отмывание денежных средств в ходе выборов, необходимо учитывать всю совокупность действующих в данной сфере регулирования международных и внутригосударственных правовых актов.

Определение понятия «отмывания» доходов от преступной деятельности дается в ряде международно-правовых документов: Конвенции $\mathrm{OOH}$ «О борьбе с незаконной перевозкой наркотиков и психотропных

полученных незаконным путем, как социальный и правовой феномен // Российский следователь. 2000. № 4.

${ }^{4}$ См.: Правовые аспекты деятельности политических партий / Под общей ред. Е.П.Дубровиной; Центральная избирательная комиссия Российской Федерации. М., 2002. С.33-35. 
средств» 1988 г.; Положении Базельского комитета по банковскому регулированию и надзору «О предотвращении незаконного использования банковской системы с целью отмывания денег» 1988 г;; Рекомендациях Специальной группы по борьбе с отмыванием денег (FATF) 1989 г.; Конвенции Совета Европы «Об отмывании, выявлении, изъятии и конфискации доходов от преступной деятельности» 1990 г.; Директиве Совета Европы «О предотвращении использования финансовой системы с целью отмывания денег» 1991 г.; Типовых правилах Межамериканской комиссии по контролю за наркотиками Организации Американских Государств против преступлений, связанных с отмыванием денег, полученных от незаконной перевозки наркотиков и связанных с этим преступлений 1992 г.

В России законодательная база по противодействию отмыванию доходов, полученных преступным путем, начала создаваться лишь во второй половине 90-х годов. Впервые уголовная ответственность за легализацию (отмывание) денежных средств или иного имущества, приобретенных незаконным путем, была установлена ст. 174 Уголовного кодекса Российской Федерации от 13 июля 1996 г. В августе 2001 года был принят Федеральный закон «О противодействии легализации (отмыванию) доходов, полученных преступным путем», который вступил в силу 1 февраля 2002 года ${ }^{5}$. Этот же закон ввел новый состав преступления - ст. $174^{1}$ УК РФ $\Phi^{6}$. Таким образом, международно-правовые положения в сфере борьбы с «отмыванием» денежных средств были восприняты национальным законодательством Российской Федерации.

${ }^{5}$ См.: Собрание законодательства Российской Федерации. 2001. № 33, часть 1, ст. 3418.

${ }^{6}$ В редакции Федерального закона от 30 октября 2002 года № 131-Ф3 стал именоваться Федеральным законом «О противодействии легализации (отмыванию) доходов, полученных преступным путем, и финансированию терроризма» // Собрание законодательства Российской Федерации. 2002. № 30, ст. 3029. 
В соответствии с п. 2 ст.3 Федерального закона от 30 октября 2002 года «О противодействии легализации (отмыванию) доходов, полученных преступным путем, и финансированию терроризма» легализация (отмывание) доходов, полученных преступным путем - это придание правомерного вида владению, пользованию или распоряжению денежными средствами или иным имуществом, полученными в результате совершения преступления.

Преступления, предусмотренные ст. 193 УК РФ «Невозвращение из-за границы средств в иностранной валюте», ст. 194 УК РФ «Уклонение от уплаты таможенных платежей», ст. 198 УК РФ «Уклонение гражданина от уплаты налога» и ст. 199 УК РФ «Уклонение от уплаты налогов с организаций» выведены за пределы сферы действия закона.

В наиболее общем виде отмыванием денежных средств в ходе выборов можно считать придание денежным средствам или (и) иному имуществу, полученным кандидатами, политическими партиями, избирательными блоками незаконным путем на цели подготовки и проведения выборов, действительного или мнимого статуса легитимности.

В ходе выборов денежные средства могут отмываться через различные структуры:

- специально создаваемые политические партии или избирательные блоки, обладающие правом выдвижения кандидатов в депутаты, с помощью продажи «проходных» мест в партийных списках ${ }^{7}$;

- кредитные организации путем сговора отдельных кандидатов, избирательных блоков с руководством банков для размещения незаконно

7 См.: Вопросы взаимодействия избирательных комиссий с органами государственной власти при подготовке и проведении выборов с учетом требований Федерального закона «Об основных гарантиях избирательных прав и права на участие в референдуме граждан Российской Федерации»: Стенограмма межрегионального семинара председателей избирательных комиссий субъектов Российской Федерации, входящих в Центральный федеральный округ (Белгород, 3 декабря 2002 года) / Центральная избирательная комиссия Российской Федерации. М., 2003. С.11. 
полученных доходов на счетах руководимых ими банков (филиалов)) и дальнейшего использования на нужды избирательных кампаний;

- организации, оказывающие рекламные услуги (организации политических консультантов-технологов, PR-агентства), с использованием завышенных расценок на социологические опросы, а также эксклюзивного обслуживания отдельных кандидатов, избирательных объединений указанными структурами, принадлежащими финансово-промышленным группам ${ }^{8}$;

- учрежденные кандидатами, политическими партиями, избирательными блоками организации телерадиовещания, периодические печатные издания;

- службы безопасности кандидатов, избирательных объединений (частные охранные предприятия, действующие в интересах кандидатов, избирательных объединений);

- предприятия, организации, учреждения сферы услуг.

Оптимальным прикрытием отмывания денежных средств является торговля услугами, поскольку здесь нет четких правил, по которым можно проверить цены, назначаемые по согласованию сторон.

С целью отмывания денежных средств в ходе выборов лицами, заинтересованными в продвижении определенных кандидатов в органы государственной власти или местного самоуправления, может осуществляться покупка недвижимости (ценных бумаг) по ценам ниже рыночных. Затем эта собственность перепродается по полной рыночной стоимости, а полученные средства передаются на финансирование кандидатов.

В зависимости от финансовых возможностей криминальных спонсоров, стратегии организаторов выборов отмывание может приобретать характер постоянной финансовой подпитки или единовременной денежной

8 Такой путь отмывания денежных средств использовался, в частности, в период выборов губернатора Приморского края 19 декабря 1999 года. 
выплаты кандидату, политической партии. Наиболее целесообразным с позиций представителей организованных преступных групп является постепенное отмывание небольших сумм денежных средств в ходе выборов, не подлежащих обязательному контролю согласно п.2 ст.3 Федерального закона от 30 октября 2002 года «О противодействии легализации (отмыванию) доходов, полученных преступным путем, и финансированию терроризма» ${ }^{9}$. Использование единовременной денежной выплаты обычно сопровождается смешиванием денег, полученных законным и незаконным путем. Отмывание денежных средств может осуществляться на всех стадиях выборов или на отдельной стадии.

Для лиц, заинтересованных в отмывании денежных средств в ходе выборов, более предпочтительными являются расчеты в наличном порядке. Однако в действительности спонсоры кандидатов и избирательных блоков не всегда располагают возможностями для передачи крупных сумм наличными. Поэтому в целях финансирования избирательных кампаний практикуются и безналичные расчеты ${ }^{10}$. Схема с использованием безналичных расчетов работает как в «натуральной» форме (представители организованных преступных групп Калининградской области на выборах депутатов Калининградской областной Думы 4 марта 2001 года использовали для подкупа избирателей мясо-молочные продукты с подконтрольных заводов), так и с участием кредитных организаций. Как правило, в случае использования для отмывания денежных средств подконтрольных криминалитету юридических лиц их руководство негласно сотрудничает с определенными кредитными организациями и обналичивает необходимые денежные суммы.

9 См.: Собрание законодательства Российской Федерации. 2002. № 44, ст. 4296.

${ }^{10}$ В соответствии с ч.4 ст.59 Федерального закона «Об основных гарантиях избирательных прав и права на участие в референдуме граждан Российской Федерации» расчеты между кандидатом, избирательным объединением, избирательным блоком и юридическими лицами осуществляются только в безналичном порядке. 
Как свидетельствует зарубежная практика, аналогичные формы отмывания денежных средств в ходе выборов используются и в ряде иностранных государств ${ }^{11}$. К примеру, по данным экспертов, в США распространены 3 основные схемы, по которым осуществляется отмывание денег в период выборов ${ }^{12}$.

Во-первых, внесение средств через подставных лиц. Эта схема предполагает наличие источника, из которого производится передача небольших и абсолютно законных сумм третьим лицам, которые, в свою очередь, направляют эти средства от своего имени в комитеты предвыборных кампаний, указанные таким источником.

Во-вторых, выставление фиктивных счетов. Согласно этой схеме, должностные лица, занимающие высокие посты, просят третьих лиц (которыми обычно бывают их подчиненные служащие) осуществить пожертвование от своего имени в разрешенных законом пределах в пользу определенного комитета предвыборной кампании, а затем разрешают таким лицам выставить фиктивные счета или выплачивают им фиктивные премии.

В-третьих, платежи, производимые третьей стороной. Комитет предвыборной кампании направляет выставленные ему счета напрямую в организацию или лицу, осуществлющему противозаконное финансирование, которые оплачивают их, что позволяет официальным организаторам предвыборной кампании избежать отчетности по этим средствам;

Перечисленные формы отмывания постоянно изменяются и совершенствуются. Наиболее «удачные» из них, существующие в зарубежной практике, активно используются российскими «коллегами». В то

${ }^{11}$ Примечательно, что во Франции Законом от 19 января 1995 года № 95-65 введен запрет на пожертвования в избирательные фонды юридических лиц. 12 См.: Материалы для брифинга: Выборы и организация избирательного процесса в Соединенных Штатах Америки. Международный Фонд Избирательных Систем. М.: Институт развития избирательных систем, 2000. C. 135-136. 
же время, с учетом условий конкретных избирательных кампаний и развития национального законодательства о выборах, в Российской Федерации возникают новые формы и способы отмывания денежных средств в ходе выборов.

Так, начиная с 1997 года в ходе избирательных кампаний, проходящих в г. Санкт-Петербурге и Ленинградской области была зафиксирована следующая форма отмывания денежных средств в ходе выборов. Некоторые преступные группы качестве гарантий по обеспечению кредитов использовали энергоносители ряда организаций. Полученные таким образом заемные средства вкладывались в другие сферы экономической деятельности, а долговые обязательства не исполнялись. Аналогичным образом поступали со следующей организацией. Часть вырученных таким образом денежных средств расходовалась на проведение избирательных кампаний в интересах отдельных лиц и политических партий.

В связи с интенсивным развитием компьютерных сетей, появлением электронных карточек и иных платежных средств следует прогнозировать появление соответствующих форм и способов отмывания денежных средств, в том числе и в ходе выборов.

Современная выборная практика показывает, что значительные объемы денежных средств, используемые кандидатами, избирательными блоками в процессе организации и проведения выборов, делают проблему отмывания денежных средств в ходе выборов весьма актуальной.

C учетом высокой степени общественной опасности отмывания денежных средств противоправные тенденции в финансировании избирательных кампаний стали объектом пристального внимания не только правоохранительных органов, но и законодательных органов государственной власти Российской Федерации ${ }^{13}$. В законодательстве о

${ }^{13}$ См. Постановление Совета Федерации Федерального Собрания Российской Федерации от 4 сентября 1998 года № 392 - СФ «Об информации и.о. Министра внутренних дел Российской Федерации и Директора ФСБ России о 
выборах появились новеллы, ограничивающие возможности незаконного финансирования кандидатов и политических партий. В соответствии с п.п. «3» и «и» п.23 ст.38 Федерального закона от 12 июня 2002 года «Об основных гарантиях избирательных прав и права на участие в референдуме граждан Российской Федерации» основаниями отказа в регистрации кандидата, списка кандидатов стали являться использование при финансировании избирательной кампании помимо средств собственного избирательного фонда иных денежных средств, составляющих более 5 \% от установленного законом предельного размера расходования средств избирательного фонда; превышение размера расходования из избирательного фонда более чем на 5 \% от установленного законом предельного размера расходования средств избирательного фонда ${ }^{14}$. По сравнению с предыдущей редакцией настоящего Федерального закона от 19 сентября 1997 года, когда основанием отказа в регистрации было существенное нарушение порядка создания избирательного фонда и расходования его средств, новая норма снизила возможность произвольного (выборочного) правоприменения.

Федеральный закон от 10 января 2003 года «О выборах Президента Российской Федерации» установил, что предельная сумма всех расходов кандидата из средств его избирательного фонда не может превышать 250 млн. рублей (для кандидата, по которому назначено повторное голосование, - 300 млн. рублей $)^{15}$. В соответствии с Федеральным законом от 20 декабря 2002 года «О выборах депутатов Государственной Думы Федерального Собрания Российской Федерации» для кандидата в депутаты Государственной Думы предельная сумма всех расходов из средств избирательного фонда не может превышать 6 млн. рублей. В отношении

криминогенной обстановке в Российской Федерации, принимаемых мерах по укреплению законности, пресечению фактов коррупции и проникновения криминальных элементов в органы государственной власти / Собрание законодательства Российской Федерации. 1998. № 37, ст. 4553.

${ }^{14}$ См.: Российская газета. 2002. 15 июня.

15 Там же. 2003. 16 января. 
политической партии, избирательного блока на выборах в Государственную Думу предельная сумма всех расходов из средств избирательного фонда составляет 250 млн. рублей ${ }^{16}$.

В старой редакции закона предельная сумма всех расходов из средств избирательного фонда кандидата не могла превышать 2 млн. рублей, а избирательного фонда политической партии, избирательного блока - 150 млн. рублей. Появление этой новеллы обусловлено тем, что повышение размера избирательного фонда, как ожидается, будет способствовать выведению из оборота или сведению к минимуму нелегальной части денежных средств

Федеральные законы «О выборах Президента Российской Федерации» (ст. 58) и «О выборах депутатов Государственной Думы Федерального Собрания Российской Федерации» (ст.66) предусмотрели, что основная доля в избирательном фонде кандидатов теперь формируется за счет средств, которые выделены кандидату выдвинувшей его политической партией. В развитие данного положения при непосредственном участии Контрольноревизионного управления ЦИК России была разработана новая, более подробная форма сводного финансового отчета кандидата и политической партии. Предполагается, что указанные правовые меры позволят усилить контроль политических партий за движением денежных средств и уменьшить возможности криминального влияния на финансирование выборов.

Согласно действующему законодательству о выборах устанавливаются различные виды контроля за финансированием избирательной кампании. Если целевая направленность избирательных фондов дает возможность избирательным комиссиям осуществлять текущий контроль за законностью финансирования предвыборной агитации кандидатов, избирательных блоков, то итоговым контролем является предоставление избирательным комиссиям финансовых отчетов.

${ }^{16}$ Там же. 2002. 25 декабря. 
Важное значение для документирования правоохранительными органами противоправной деятельности в ходе финансирования избирательных кампаний имеют положения Федерального закона от 30 октября 2002 года «О противодействии легализации (отмыванию) доходов, полученных преступным путем, и финансированию терроризма». В соответствии с ч.3 ст.7 настоящего Федерального закона вводится пятилетний срок хранения документации, содержащей сведения по операциям с денежными средствами или иным имуществом, подлежащим обязательному контролю.

В то же время Федеральный закон «О противодействии легализации (отмыванию) доходов, полученных преступным путем, и финансированию терроризма» предусматривает меры, направленные на противодействие отмыванию денежных средств, к которым относятся: обязательные процедуры внутреннего контроля, обязательный контроль, запрет на информирование клиентов и иных лиц о принимаемых мерах противодействия отмыванию денежных средств, и иные меры, принимаемые в соответствии с федеральными законами. Подобная градация вызывает некоторые возражения.

Во-первых, в законе перечисленные меры изложены непоследовательно (сначала раскрывается обязательный контроль, а затем упоминаются меры внутреннего контроля). Во-вторых, как представляется, запрет на информирование о принимаемых мерах противодействия отмыванию не может быть отнесен к числу мер, поскольку, по сути, является гарантией противодействия отмывания доходов, полученных преступным путем. Наконец, не совсем ясно, о каких иных мерах противодействия идет речь в законе.

Исходя из этого, предлагается рассмотреть комплекс организационных и правовых мер, не указанных в законе «О противодействии легализации (отмыванию) доходов, полученных преступным путем, и финансированию 
терроризма», с помощью которых правоохранительные органы могут противодействовать отмыванию денежных средств в ходе выборов.

Предлагаемые организационные меры включают меры по выявлению признаков отмывания, а также меры по предупреждению и пресечению отмывания денежных средств в ходе выборов.

Меры по выявлению направлены на сбор и добывание информации о признаках отмывания, возможно имеющихся в деятельности кандидатов и избирательных объединений, подозреваемых в причастности к противоправной деятельности.

Признаки отмывания денежных средств в ходе выборов являются характерными для отдельных стадий избирательного процесса, но могут проявляться и на протяжении всей избирательной кампании.

Нужно отметить, что значительный объем денежных средств, связанных с финансированием отдельных кандидатов, избирательных блоков легализуется еще в предвыборный период или сразу после назначения выборов. Поэтому сначала выделим признаки отмывания денежных средств, относящзиеся к предвыборному периоду и стадии назначения выборов.

Это могут быть как неофициальные контакты предполагаемых кандидатов (их уполномоченных представителей) с руководством финансово-промышленных групп, бюджетообразующих предприятий, кредитных организаций о возможной финансовой поддержке на выборах, так и тайные контакты предполагаемых кандидатов (их уполномоченных представителей) с лидерами организованных преступных групп о возможном финансировании избирательной кампании.

Признаки отмывания денежных средств, относящиеся к стадии выдвижения и регистрациии кандидатов могут проявляться в форме: выделения официально неучтенных денежных средств на составление социального паспорта региона проведения выборов, разработку стратегии ведения и календарного плана избирательной кампании; внедоговорных авансовых выплат имиджмейкерам, консультантам-политтехнологам, 
сотрудникам PR-агентств, доверенным лицам кандидатов; формирования структур, организационно не связанных с кандидатами и избирательными объединениями, но действующих в их интересах (к примеру, клубов избирателей «За свободные и честные выборы»); создания и оснащения спецтехникой служб безопасности, действующих в период выборов как в интересах конкретного кандидата, так и в интересах представляющих его финансово-промышленных групп; включения в число доверенных лиц кандидатов членов организованных преступных групп; приобретения конспиративных помещений для важных деловых встреч кандидата и возможной работы избирательного штаба в условиях оперативной заинтересованности правоохранительных органов; деятельности внештатных сборщиков подписей (на бездоговорной форме оплаты); оплаты подписей избирателей; неофициального премирования наиболее активных доверенных лиц и групп сборщиков подписей; подкупа и подарков отдельным членам избирательных комиссий; установления неофициальных контактов на возмездной основе в среде сотрудников правоохранительных и других государственных органов, обеспечивающих организацию и проведение выборов (администрация, налоговые органы, прокуратура, территориальные подразделения МВД, Минюста) с целью регулярного получения информации в интересах поддержки принятия решений; нахождения в составе учредителей политических общественных объединений участников и ближайшего окружения организованных преступных групп; продажи мест в партийных списках.

К признакам отмывания денежных средств, относящимся к стадии финансирования выборов, следует отнести: нарушения порядка формирования избирательного фонда кандидата; взносы в избирательный фонд кандидата и формирование избирательного залога с участием физических и юридических лиц с сомнительной деловой репутацией, в том числе связанных с организованной преступностью; анонимные пожертвования в избирательный фонд кандидатов; пожертвования в 
избирательный фонд через «подставных» физических лиц за определенное вознаграждение, в том числе по украденным (потерянным документам); открытие счетов юридических лиц с зачислением на них денежных средств уполномоченных представителей кандидатов по финансовым вопросам, доверенных лиц, их ближайшего окружения и последующим переводом на избирательный счет кандидата; наличие каналов поступления денежных средств кандидата помимо избирательного фонда; оформление приобретаемого кандидатами, избирательными объединениями имущества на других лиц; приобретение имущества по очевидно заниженной стоимости; предоставление банковских кредитов под конкретные политические гарантии зарегистрированных кандидатов; зачисление на определенный вклад денежных средств, которые затем переводятся в другие банки (филиалы), в том числе на избирательный счет кандидата; неоднократное осуществление операций, при которых один и тот же финансовый инструмент (например, пакет ценных бумаг) многократно продается и затем выкупается в сделках подконтрольными кандидату (поддерживающими его) финансовопромышленными группами, бюджетообразующими предприятиями, организациями; «двойная» бухгалтерия избирательных штабов кандидатов; эксклюзивное обслуживание отдельных кандидатов, избирательных объединений PR-агентствами, принадлежащими финансово-промышленным группам; установление завышенных расценок на перечень работ и услуг, выполненных в интересах кандидатов, избирательных объединений; внесение в договоры о выполненных работах заведомо ложных сведений, касающихся размеров произведенных кандидатами выплат, юридических адресов, реквизитов сторон; нецелевое использование бюджетных средств, выделенных на проведение выборов, избирательными комиссиями; несвоевременное представление финансовых отчетов кандидатами.

Признаки отмыввания денежных средств, относящуиеся $к$ стадии информациионного обеспечения выборов, охватывают: выделение официально неучтенных денежных средств на разработку информационно-агитационных 
материалов и медиаплана избирательной кампании; установление неофициальных контактов на возмездной основе с должностными лицами СМИ и информационных телекоммуникационных сетей; многократное возрастание тиража отдельных периодических изданий (времени трансляции некоторых радиостанций) в период избирательных кампаний; появление СМИ-«однодневок»; активное использование отдельными кандидатами в своих интересах СМИ, учрежденных «подставными» кандидатами («кандидатами-дублерами»); привлечение некоторыми избирательными объединениями и кандидатами известных деятелей «шоу-бизнеса» и разного роды агитбригад, не оплаченных за счет средств избирательного фонда; широкое освещение в СМИ участия кандидатов в политически-нейтральных культурно-зрелищных мероприятиях; явный и скрытый подкуп избирателей в ходе массовых агитационных мероприятий (раздача малоценных подарков, предметов бытового обихода, предоставление бесплатных услуг или выполнение работ по сниженным расценкам в интересах избирателей) $)^{17}$; распространение анонимных агитационных материалов в поддержку кандидата, что также может быть частью выборной стратегии конкурентов, направленной на «снятие» кандидата; выделение денежных средств на конкретные выборные мероприятия под прикрытием создания Интернет- и полиграфической продукции; реальная стоимость агитационных мероприятий значительно превосходит размеры избирательного фонда кандидата;

Признаки отмывания денежных средств, относящиеся к стадии голосования $u$ определения результатов выборов, включают: подкуп избирателей непосредственно в день голосования (т.н. технологии «гусеница», «вереница»); предложения бесплатных юридических услуг и различных льгот; организация в удаленных и труднодоступных местностях

17 Одним из способов скрытого подкупа избирателей в г. Санкт-Петербурге стали т.н «избирательные договоры». Заключив такой договор и получив определенную сумму, избиратель становился «агитатором». Фактически же, таким образом покупались голоса в пользу определенного кандидата. 
транспортных маршрутов для лиц, желающих проголосовать; участие отдельных кандидатов, избирательных объединений через подставных лиц в распродаже товаров на избирательных участках в день голосования.

К признакам отмывания денежных средств, относящиимся $к$ послевыборному периоду, следует отнести: принятие выборными должностными лицами нормативных актов и государственно-властных решений в интересах конкретных финансово-промышленных групп, бюджетообразующих предприятий и кредитных организаций (создание условий благоприятствования при проведении коммерческой деятельности, необоснованное вложение денежных средств в уставный капитал, незаконная передача собственности); назначение отдельных лиц, осуществлявших финансовую поддержку кандидатов, в аппарат управления, на наиболее ответственные должности в сфере производства (как правило, в бюджетообразующих предприятиях, естественных монополиях), кредитных организациях; неофициальное покровительство и извлечение доходов от деятельности подконтрольных предприятий; попытки получить права на управление строительными организациями и распределение их прибылей (эта схема позволяет не только отмывать преступно полученные денежные средства, но и получать сверхприбыли); использование предприятий, учреждений и организаций сферы услуг (заведомо убыточные магазины, рестораны, автосалоны и т.д ).

Основной практической проблемой борьбы с отмыванием денежных средств в ходе выборов является трудность выявления и привлечения к ответственности коммерческих организаций и банковских учреждений, создаваемых для прикрытия запрещенной деятельности в период выборов. Правоохранительным органам необходимо собрать доказательства отсутствия намерений осуществлять предпринимательскую или банковскую деятельность. При организации работы по выявлению фактов и признаков, форм и методов отмывания денежных средств в ходе выборов следует 
отметить, что аналогичные сложности возникают в связи с мнимыми и притворными гражданско-правовыми сделками.

Наибольшую сложность в оценке степени виновности представляет такая категория субъектов отмывания, как организаторы избирательной кампании, ведущие работу от имени и по поручению какого-либо кандидата или политической партии. Дискуссионным является вопрос о том, кто именно должен нести ответственность за финансовые злоупотребления в ходе выборов. С одной стороны, применение санкций к кандидату или руководству партии за мелкие финансовые нарушения, допущенные не по их воле и без их ведома, представляется недостаточно обоснованным. С другой стороны, подобная мотивация может вызвать соблазн нарушить закон и уйти от ответственности. Многие зарубежные страны переняли так называемую «вестминстерскую модель», согласно которой кандидат может делегировать полномочия по проведению избирательной кампании своему представителю, наделяемому правом распоряжения избирательным фондом. Поскольку такой представитель назначается кандидатом по его собственному усмотрению, то последний также несет ответственность за правонарушения этого лица.

В российском законодательстве о выборах право распоряжаться средствами избирательных фондов принадлежит создавшим их кандидатам, избирательным объединениям, блокам, уполномоченным представителям по финансовым вопросам (п.2 ст.59 Федерального закона «О выборах Президента Российской Федерации», п.4 ст.67 Федерального закона «О выборах депутатов Государственной Думы Федерального Собрания Российской Федерации»). Таким образом, в отечественной практике вопрос об ответственности кандидатов и организаторов выборов за финансовые правонарушения решен на законодательном уровне.

Для сбора и добывания информации о признаках отмывания, возможно имеющихся в деятельности спонсоров кандидатов и избирательных объединений, необходимо проводить налоговые проверки, использовать сведения, материалы и документы из Единого государственного реестра 
налогоплательщиков Министерства по налогам и сборам и его территориальных органов. Тем более что п.10 ст.62 Федерального закона «О выборах Президента Российской Федерации» и п.6 ст.70 Федерального закона «О выборах депутатов Государственной Думы Федерального Собрания Российской Федерации» предписывают налоговым органам предоставлять по обращениям ЦИК Российской Федерации копии сводных финансовых отчетов политических партий, а также иных общероссийских общественных объединений, входящих в избирательные блоки, выдвинувшие зарегистрированные федеральные списки кандидатов; имеющиеся сведения о результатах проверок, в том числе о выявленных нарушениях финансовой деятельности указанных политических партий, иных общероссийских общественных объединений.

Большое значение для выявления фактов незаконного финансирования имеет использование функционального комплекса задач «Финансы» Государственной автоматизированной системы «Выборы». Данный функциональный комплекс призван обеспечивать бухгалтерский учет, планирование, исполнение и контроль исполнения бюджетов избирательных кампаний.

В то же время сбор, анализ и обработка информации в системе ГАС «Выборы» сегодня осуществляется с задержками. Как ни парадоксально, но причиной тому являются положения п.7 ст.59 Федерального закона «Об основных гарантиях избирательных прав и права на участие в референдуме граждан Российской Федерации», согласно которым кредитная организация держатель специального избирательного счета по требованию соответствующей комиссии, кандидата, избирательного объединения (блока) обязана периодически поставлять им информацию о поступлении и расходовании средств. В тексте комментируемого закона следует заменить слово «периодически» на «постоянно». В целях развития ГАС «Выборы» необходимо реализовать такой режим автоматизированного функционирования ФКЗ «Финансы», который бы позволил получать 
информацию обо всех финансовых поступлениях на избирательные счета кандидатов в реальном времени и незамедлительно передавать эту информацию кандидатам, избирательным объединениям, вышестоящим комиссиям.

В ходе оперативно-розыскных мероприятий в отношении противоправной предпринимательской деятельности юридических лиц, подозреваемых в причастности к отмыванию денежных средств, следует использовать сведения Министерства юстиции Российской Федерации, а также уполномоченных органов, осуществляющих регистрацию юридических лиц, о зарегистрированных в территориальных органах и учреждениях юстиции юридических лицах, осуществивших добровольные пожертвования в избирательные фонды.

Другая группа организационных мер противодействия отмыванию денежных средств в ходе выборов охватывает меры предупреждения и пресечения. Эти меры предусматривают: установление контроля за финансовыми потоками в процессе организации и проведения выборов; разработку организованных преступных групп и коррумпированных должностных лиц, обеспечивающих организацию и проведение выборов; негласное затруднение деятельности, направленной на отмывание; дискредитацию обоснованно подозреваемых в причастности к преступной деятельности спонсоров кандидатов; реализацию через СМИ и официальные возможности налоговых, контролирующих и правоохранительных органов легализованной информации об отмывании конкретными кандидатами, избирательными объединениями денежных средств в ходе выборов.

В рамках проводимой работы по выявлению, предупреждению и пресечению правонарушений на стадии финансирования выборов правоохранительные органы должны найти исчерпывающие ответы на следующие вопросы:

1.Соблюдается ли установленный Федеральным законом «Об основных гарантиях избирательных прав и права на участие в референдуме граждан 
Российской Федерации» порядок образования избирательных фондов и не участвуют ли в этой деятельности юридические и физические лица, которым запрещено это делать.

2.Используются ли средства избирательных фондов исключительно на цели, определенные законодательством о выборах (п.3 ст.59 данного Закона).

3.Соблюдаются ли предусмотренные федеральным законодательством правила о предоставлении кандидатами на выборный пост отчетов в избирательную комиссию о размерах и расходовании избирательных фондов.

4.Исполняют ли избирательные комиссии функции контроля за порядком формирования и расходования средств избирательных фондов кандидатов, избирательных объединений, избирательных блоков.

В процессе работы по сигналам об имеющихся нарушениях законодательства на стадии финансирования правоохранительные органы могут через возможности прокуратуры направлять в контрольноревизионные службы избиркомов акты прокурорского реагирования. В ходе собственной проверки, инициированной по материалам правоохранительных органов, прокурор может также выявлять наличие фактов нецелевого использования средств избирательного фонда (п.3 ст.59 Федерального закона «Об основных гарантиях избирательных прав и права на участие в референдуме граждан Российской Федерации»).

Материалы, содержащие данные о совершении лицом (группой лиц) административных правонарушений, предусмотренных ст.ст. 5.17, 5.18, 5.21 Кодекса Российской Федерации об административных правонарушениях (КоАП РФ), передаются инспекторам Счетной палаты для составления протоколов об административных правонарушениях на стадии финансирования выборов, а об административных правонарушениях, предусмотренных ст.5.16, ч.1.ст. 5.17, ст. 5.18 - 5.20 КоАП РФ уполномоченным членам избирательных комиссий с правом решающего 
голоса $^{18}$. При наличии данных о признаках преступлений, предусмотренных ч.ч. 2 и 3 ст.160 («присвоение или растрата»), ст. 172 («незаконная банковская деятельность»), ст.173 («лжепредпринимательство»), ст.174 («легализация (отмывание) денежных средств или иного имущества, приобретенных незаконным путем») УК РФ орган расследования возбуждает уголовное дело и проводит предварительное расследование.

Необходимо отметить, что значительные трудности возникают при доказывании в суде фактов финансовых нарушений со стороны кандидата до представления им официального отчета об операциях, совершенных на средства из избирательного фонда. Причем сложность доказывания по данной категории дел многократно возрастает, если определенные услуги или материальные ценности предоставляются кандидату в кредит ${ }^{19}$.

Как свидетельствует практика избирательных кампаний, регламентация противодействия отмыванию денежных средств в ходе выборов нуждается в дополнительных правовых механизмах. Так, представляется, что в качестве компенсации части расходов на избирательную кампанию кандидатам и избирательным блокам должны выплачиваться государственные дотации. В случае нарушения правил формирования и расходования средств избирательных фондов кандидата или политическую партию следует лишать подобных дотаций.

Возрастание роли политических партий в избирательном процессе требует должного отражения прозрачности их финансирования. Не случайно в Послании Президента России В.Путина Федеральному Собранию Российской Федерации отмечается, что «механизмы

18 См.: Российская газета. 2001. 31 декабря.

19 Примером может служить дело по жалобам на действия кандидата на должность губернатора Тульской области С. и заявлениям об отмене решения избирательной комиссии Тульской области о регистрации С. кандидатом на указанную должность, рассмотренное судебной коллегией по гражданским делам Тульского областного суда // Справка Генеральной прокуратуры к совещанию заместителей председателей избирательных комиссий субъектов РФ по вопросам работы контрольно-ревизионных служб (Москва, 19 апреля 2001 года). 
финансирования политических партий остаются для избирателей тайной за семью печатями» ${ }^{20}$.

Из п.5. ст.59 Федерального закона «Об основных гарантиях избирательных прав и права на участие в референдуме граждан Российской Федерации» представляется целесообразным убрать фразу: «Допускаются добровольное бесплатное личное выполнение гражданином работ, оказание им услуг по подготовке и проведению выборов, референдума без привлечения третьих лиц». Фактически данная норма позволяет легально привлекать граждан для выполнения работ и оказания услуг на возмездной основе без оплаты из средств соответствующего избирательного фонда кандидата.

П.1 ст.58 комментируемого Федерального закона предусматривает, что законом субъекта Российской Федерации может быть установлено, что на выборах в органы местного самоуправления при определенном числе избирателей в избирательном округе (но не более пяти тысяч избирателей) создание кандидатом избирательного фонда необязательно при условии, что финансирование кандидатом своей избирательной кампании не производится. Думается, что на местном уровне это еще больше стимулирует подкуп избирателей и затруднит работу правоохранительных органов по противодействию отмыванию денежных средств в ходе выборов.

${ }^{20}$ См.: Российская газета. 2003. 17 мая. 